\title{
Design it with LSCs; an exploration of applications for Luminescent Solar Concentrator PV technologies.
}

\author{
Wouter Eggink \& Angèle Reinders \\ University of Twente, Faculty of Engineering Technology, Enschede, 7550AE, the Netherlands
}

\begin{abstract}
This paper shows the results of a design study on possible applications for Luminescent Solar Concentrator PV technologies. The study focused on product integration of LSC PV technologies and was executed by students of Industrial Design Engineering at University of Twente (NL). In total 16 different and highly innovative conceptual designs resulted from this project, which were prototyped at scale to show their feasibility and integration features.

In this paper we present several concepts, and discuss relevant findings for the integration of LSC PV technologies in future products and buildings. It is shown that the typical material properties of LSCs; low cost, colorful, bendable, and transparent do not only offer a lot of design freedom, but also offer excellent possibilities to incorporate this technology into the overall function and experience of applications.
\end{abstract}

Keywords — Luminescent Solar Concentrator PV, Product Integrated PV, Building Integrated PV, Design

\section{INTRODUCTION}

An increased use of PV systems can be achieved by extending the use of existing types of PV systems, or by stimulating the use of PV in new applications. This paper focuses on the latter by exploring novel applications of Luminescent Solar Concentrating PV technologies.

LSCs are light guides, often made from transparent polymer sheet materials which are doped with luminescent dyes [1, 2]. Solar radiation enters the LSC through the large top surface and is absorbed by the luminescent particles which re-emit the radiation at a longer wavelength. Subsequently, a large fraction thereof gets trapped within the light guide by means of total internal reflection. The trapping is interrupted at the interface between the light guide and the attached solar cells, where the radiation gets converted into electricity. Hence, LSCs provide a large solar radiation surface while they employ less semiconducting materials. Hence, LSC-PV modules offer a potentially lower cost per Wp [3], and more design freedom because the polymer light guides can be bent while retaining their efficiency [4]. However, despite these advantages, so far, little experience exists with the application of LSC PV technologies in modules, buildings and products. This while the design features of LSCs allow for interesting form giving such as coloring, and being flexible and transparent. For this reason we liked to explore how new PV applications based on LSC PV technologies could be by the execution of a design project.

This approach fits to the ongoing design-driven research program on product-integrated PV, which started in 2008 [5] and has led to various projects and publications in the past decade, both on the performance of product-integrated PV [610] and user experiences with these technologies [11-13], as well as design issues concerning the application of these technologies $[14,15]$. The approach also fits to the HumanTechnology Relations program of the University of Twente [16] that researches the influence of design features on the adaptation and user acceptance of innovative technologies,
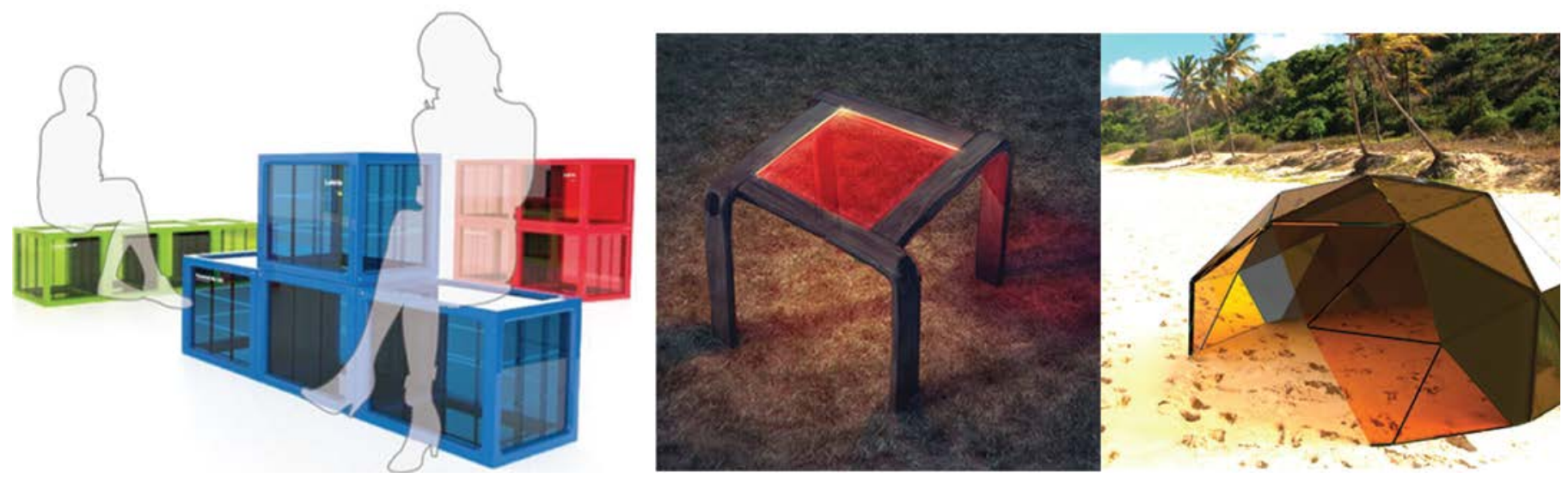

Fig. 1. Examples of conceptual designs with LSC-PV technologies, which have been developed by students of Industrial Design Engineering at University of Twente in 2016. Outdoor street furniture (left), a self-powered table (middle) and a beach shelter with integrated electronics (right). 
supported by Future Scenario Development [17-19].

\section{PROJECT CONTEXT}

As such, a design study was executed on possible applications for LSC-PV technologies within the scope of the master course 'Sources of Innovation', part of the Master in Industrial Design Engineering. This course takes 10 weeks and is especially targeted at developing novel designs for innovative technologies [20]. In the past this approach was also successfully applied to designing with Concentrating PV and other PV technologies [21, 22]. Moreover, the course is supported by a book on designing with sustainable energy technologies [23]. In the fall of 2016 about 40 students executed a design project in groups of two or three. The end results were a feasible concept design worked out to the level of a scaled prototype. The project was supervised by the authors and contained a series of guest lectures by experts on innovation methodologies. In-depth knowledge was provided by Dr. Wilfried van Sark of Utrecht University, who is a long term expert in LSC PV technologies.

\section{PV SYSTEMS AND DESIGN}

The application of PV systems beyond primary energy production is still limited. Earlier work revealed that the design potential of PV systems is often not fully used [24]. On the other hand, a common method to improve on the application of new technologies is developing demonstrator projects. Also the design potential of innovative technologies like LSCs can be shown by demonstrators.

To explore the design potential of innovative technologies the 'Design \& Styling of Future Products' methodology [25] was developed. This method was, among other methods [8] applied throughout the design project. This methodology relies on visual innovation techniques [26], combined with a balanced application of novel styling cues on the one hand and typical, familiar styling cues on the other. The latter ensures that the design results for the innovative technologies are beyond the obvious, but still acceptable as feasible solutions.

\section{DESIGN RESUlTS}

The 16 design results of the student design projects were very diverse, due to the course's emphasis on innovation and creativity. The designed objects were; a tourist shelter, a garden fence, greenhouse panels, safety staircases, parking assistance in the form of trees, outdoor tables, a casing to charge cell phones, a labyrinth for parks, self-powering ebikes, outdoor furniture, a sundial and a colorful bike parking with integrated LSC PV technologies. Three of these designs are shown in Figure 1, and in the following we would like to highlight four other examples which represent the broad application possibilities of the LSC technology on several dimensions; scale (big-small), application purpose (professional-leisure), and user experience (active-passive).

\section{A. Example I: AlliSee LSC-Boat}

This design makes full use of the design potential of LCS technology with respect to the possibilities for the realization of three dimensional shapes. The project presented a modular design for a small electrically powered dinghy for leisure activities, such as snorkeling and fishing (Figure 2).

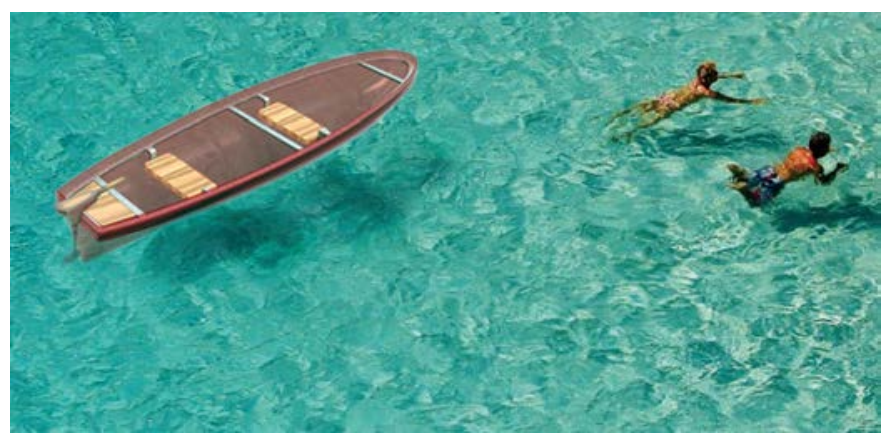

Fig. 2. 'Allisee' transparent boat concept by Jullian Claus, Rosan Harmens and Hieu Nguyen.

The transparency of the LSC material adds to the experience by making the underwater world visible to the user. The solar cells that are needed to catch the light that is collected in the LSC hull are located in the reinforced gangway. Segmentation of the LSC area with an additional PV cell grid would be used to minimize the self-absorption of the photons by the material (Figure 3).

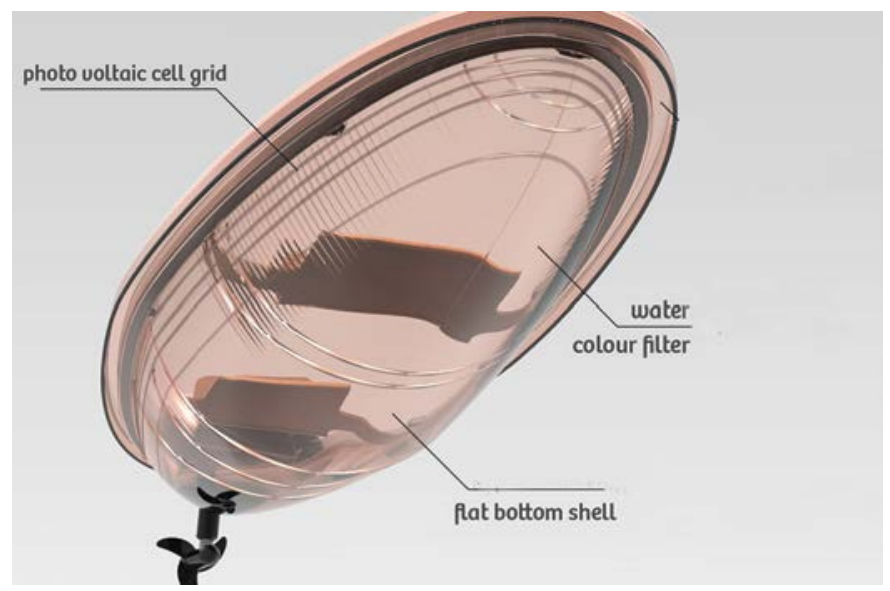

Fig. 3. LSC transparent sculpted hull design with PV cell grid. 


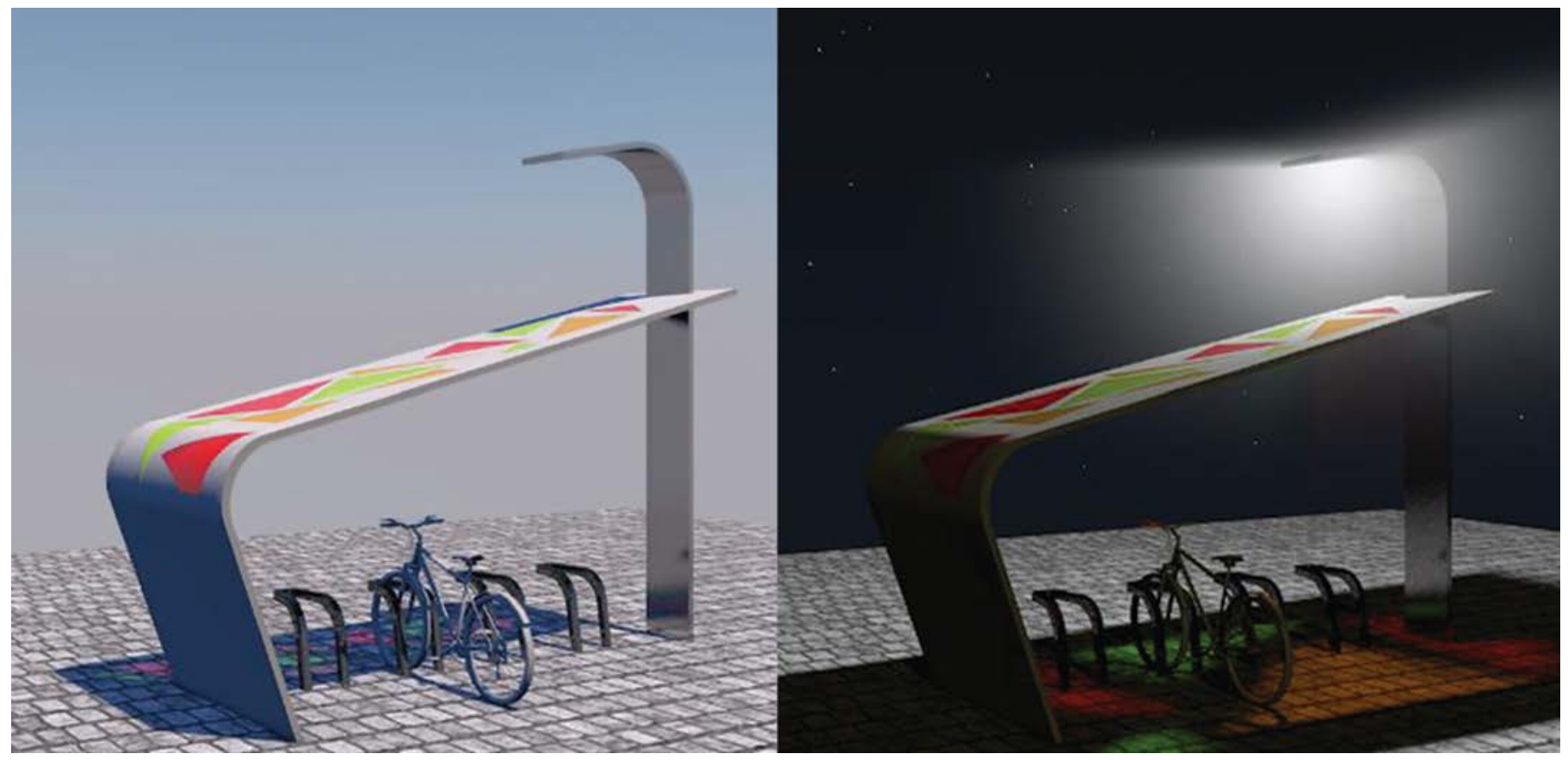

Fig. 4. Colorful effect of the LSC material in the Bike parking concept by Ruben de Noord, Eduard Tudor, and Sem Vossebeld. During daytime (left) and during the night (right)

\section{B. Example II: A bike parking shed with integrated LSCs}

In this concept, LSC material is integrated in the roof of a stand-alone bicycle parking. The LSCs generate electrical energy that can be used to charge a lantern for use during the night. The colorful shadow pattern that the LSC material sheds on the floor also adds to the consumers' experience. During the day it draws attention to the sunlight as an energy source and during the night it is supposed to support the feeling of safety (Figure 4). Additionally the LSC PV panels could generate power to charge e-bikes. Provided that the charging station is connected to the grid as well to ensure full power supply during all seasons.

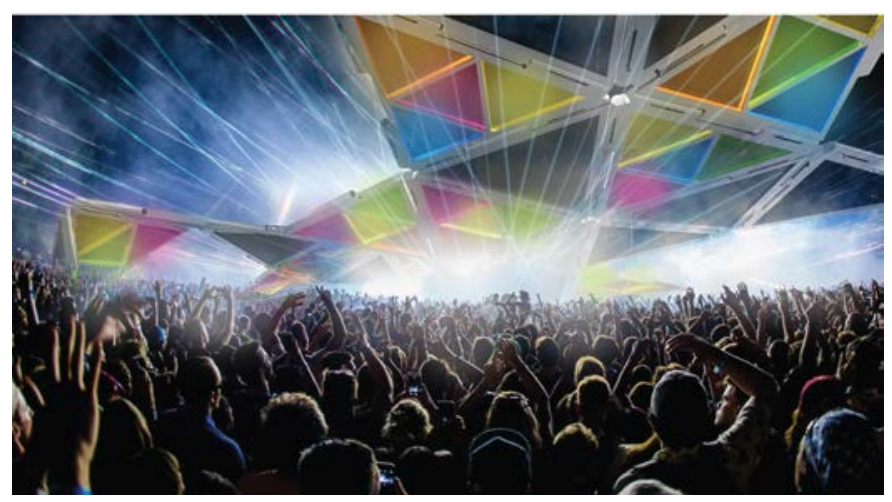

Fig. 5. Impression of the sustainable festival tent by Rolf van der Toom, Steven Oonk, and Kasper Schriek.

\section{Example III: LSC-Sustainable Festival Tent}

This sustainable festival tent uses LSC PV modules to generate a part of its own electricity consumption, while at the same time the color of the luminescent dyes is used to create a special atmosphere during day and night (Figure 5).

After dark the LSC panels are lit with the use of led strips that are placed at one edge of the triangles. At the other two edges solar cells are attached (Figure 6). The students calculated that the tent could not provide enough energy when powered by LSC-PV panels only and therefore suggested to incorporate both LSC-PV modules and conventional PV modules in a complete festival set-up (Figure 7).

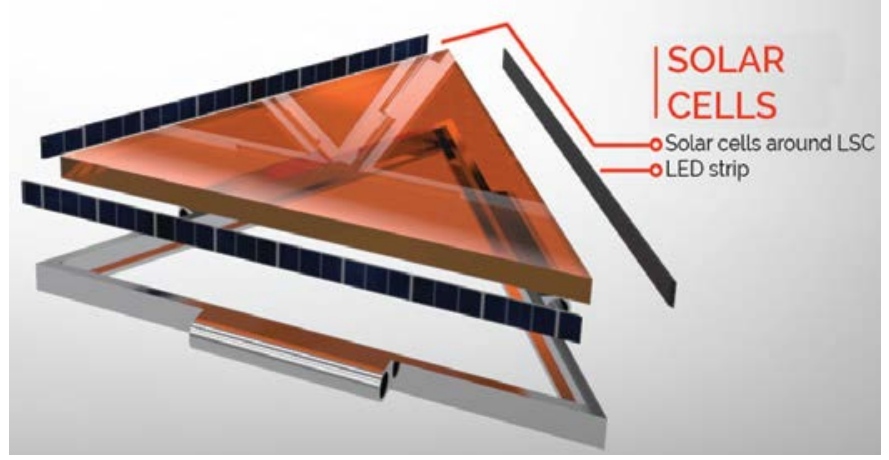

Fig. 6. Impression of the construction of the modular LSC tent segments, with Solar cells and a LED strip around the edges. 


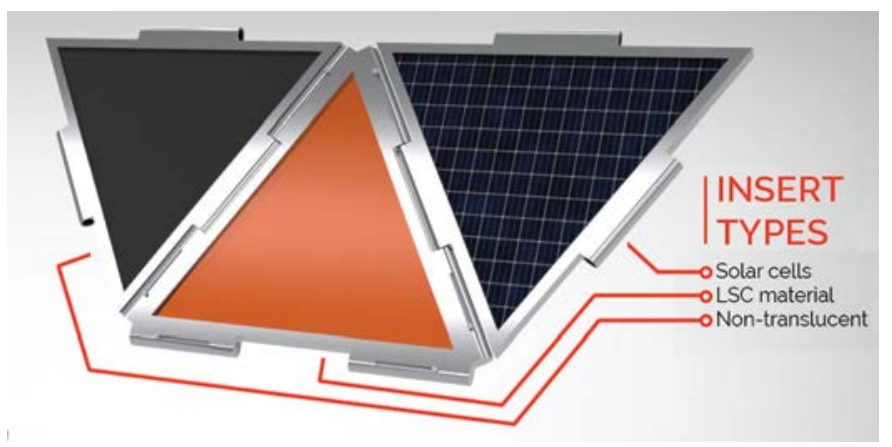

Fig. 7. Combination of LSC-PV and conventional PV modules

\section{Example IV: LSC-Safety Strips}

This concept consists of a modular system for illuminating outdoor surface edges, in particular stairs and steps (figure 8). The design is self-sufficient. With the use of LSC material in combination with solar cell strips, energy will be converted during daytime and stored by the power controller. In the evening, the energy will be used to activate the LED module inside the casing (figure 9).

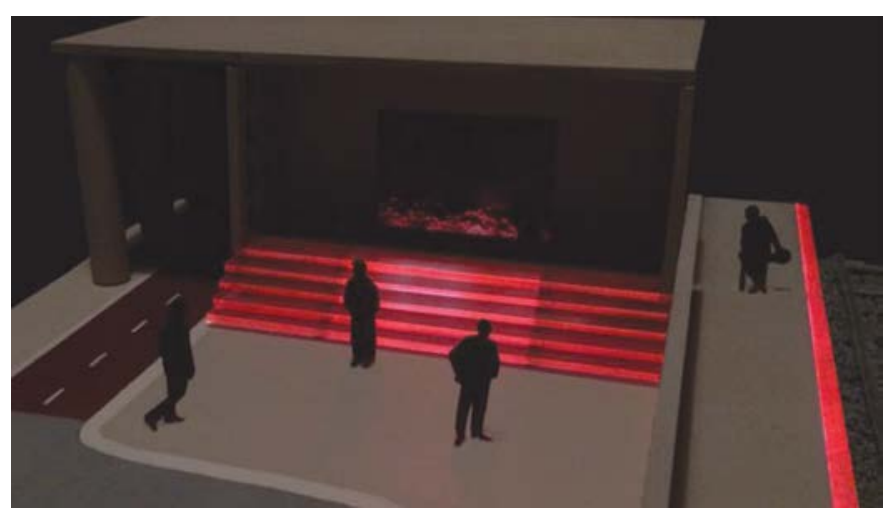

Fig. 8. Application example of LSC illuminating safety strips concept by Ashley Hogt.

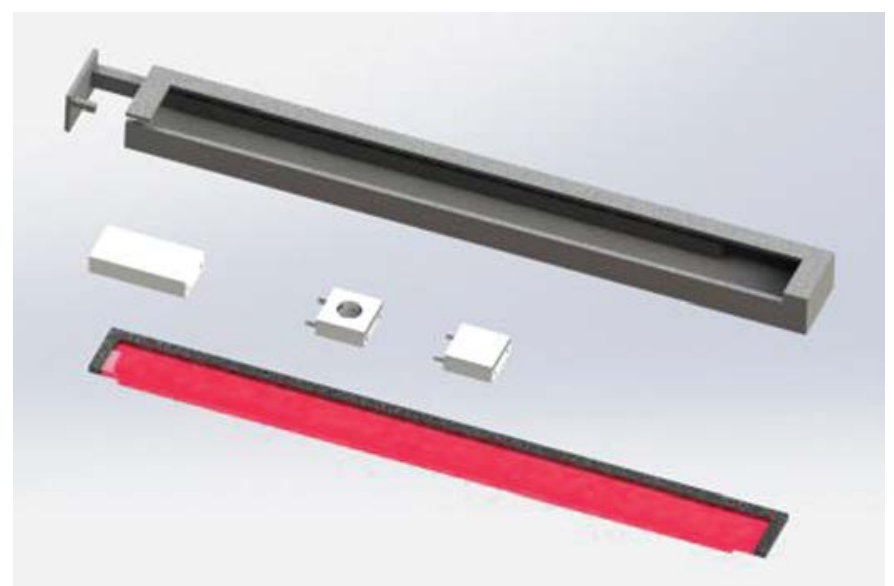

Fig. 6. Impression of the construction of the modular LSC safety strips with the LSC material (magenta) surrounded by solar cells.
The desired function of the product would be to create a feeling of safety, while walking the stairs when it is dark. To increase the engagement of the user, sensors will be used to respond to the users' movements (figure 10).
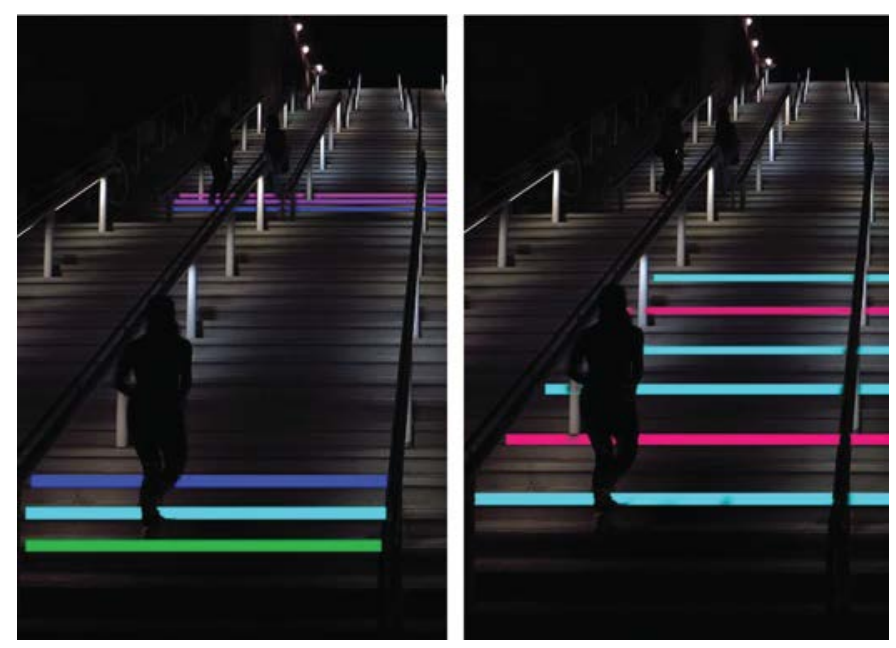

Fig. 10. Examples of the interactive use of the LSC safety strips applied on staircases.

\section{DISCUSSION}

Although the existing LSC-PV applications are primarily building components [27], this design project showed also other possibilities. Despite the assignment 'design a product using luminescent solar concentrator (LSC) technology, that can be applied in the built environment', six out of sixteen groups developed entirely other concepts. Two of these designs were furniture, one a mobile phone case, one boat (example I), and two bicycle concepts. We also saw that the students projects stretched the idea of the 'built environment' beyond limits, with for instance the festival tent concept (example III), a garden fence, and safety strips for stairs.

For all product concepts, the transparency and color of the LSC material played a major role in the appearance of the designs. This is to a certain extend as expected. However besides that, the colorfulness and transparency of the material often also played a major role in the user experience of the designs. The transparency affords the users of the boat to experience the underwater world, the colors add to the nighttime feeling of safety in the bicycle shed and ensures a permanent disco atmosphere in the festival tent. The form freedom that the material offers played in only two of the projects a decisive role in the design, which was most apparent in the LSC boat.

Another observation is that the relatively limited energy yield of LSC PV elements sometimes had to be compensated by the use of additional conventional PV modules. In other cases the energy demand of the chosen applications was kept low to fully be able to use LSC-PV technologies. 


\section{CONCLUSION}

This project showed that the typical material properties of LSCs; low cost, colorful, bendable, and transparent do not only offer a lot of design freedom, but also offer excellent possibilities to incorporate this technology into the overall function and experience of applications.

\section{REFERENCES}

[1] Doudart de la Grée, G., A. Papadopoulos, M. Debije, M. Cox, Z. Krumer, A.H.M.E. Reinders, and A. Rosemann. "A new design for luminescent solar concentrating PV roof tiles". In: Proceedings of 42nd IEEE Photovoltaic Specialists Conference. 2015. New Orleans, USA: IEEE.

[2] Reinders, A., G. Doudart de la Grée, A. Papadopoulos, A. Rosemann, M.G. Debije, M. Cox, and Z. Krumer. "Leaf Roof Designing Luminescent Solar Concentrating PV Roof Tiles". In: Proceedings of 43rd Photovoltaic Specialists Conference (PVSC). 2016. Portland: IEEE. pp. 3447-3451.

[3] Van Sark, W.G.J.H.M., K.W.J. Barnham, L.H. Slooff, A.J. Chatten, A. Büchtemann, A. Meyer, . . . D. Vanmaekelbergh, "Luminescent Solar Concentrators - A review of recent results". Optics Express, 2008. 16(26): pp. 21773-21792.

[4] Vishwanathan, B., A.H.M.E. Reinders, D.K.G. de Boer, L. Desmet, A.J.M. Ras, F.H. Zahn, and M.G. Debije, "A comparison of performance of flat and bent photovoltaic luminescent solar concentrators". Solar Energy, 2015. 112: pp. 120-127.

[5] Reinders, A.H.M.E. "Product-integrated PV applications - How industrial design methods yield innovative PV-powered products". In: Proceedings of 33rd IEEE Photovoltaic Specialists Conference. 2008. San Diego.

[6] Apostolou, G. and A.H.M.E. Reinders, "Comparison of the indoor performance of 12 commercial PV products by a simple model". Energy Science \& Engineering, 2016. 4(1): pp. 69-85.

[7] Durlinger, B., A.H.M.E. Reinders, and M.E. Toxopeus, "A comparative life cycle analysis of low power PV lighting products for rural areas in South East Asia". Renewable Energy, 2012. 41: pp. 96-104.

[8] Gorter, T. and A.H.M.E. Reinders, "A comparison of 16 polymer encapsulants for crystalline PV cells applications in PV-powered boats". Applied Energy, 2012. 92: pp. 286-297.

[9] Veldhuis, J. and A.H.M.E. Reinders, "Real time irradiance simulation for PV products and building integrated PV in a virtual reality environment". IEEE Journal of Photovoltaics, 2012. 2(3): pp. 352-358.

[10] Gorter, T., "Performance evaluation of photovoltaic boats in an early design stage - Numerical simulations with industrial design methods", PhD in Engineering Technology, 2014, University of Twente, Enschede.

[11] Apostolou, G. and A.H.M.E. Reinders, "How do users interact with PV-powered products? Investigating 100 lead users and 6 PV products". Journal of Design Research, 2016. 14(1): pp. 6693.

[12] Apostolou, G., "Design Features of Product-Integrated PV: An Evaluation of Various Factors under Indoor Irradiance Conditions", PhD in Industrial Design Engineering, 2016, Delft University of Technology, Delft.

[13] Obinna, U., P. Joore, L. Wauben, and A.H.M.E. Reinders, "Insights from stakeholders in five residential smart grid pilot projects in the Netherlands". Smart Grid and Renewable Energy, 2016. 7(1-15).

[14] Apostolou, G. and A.H.M.E. Reinders, "Overview of design issues in product-integrated PV". Journal of Energy Technology, 2014. 2(3): pp. 229-242.

[15] Reinders, A.H.M.E. and W.G.J.H.M. Van Sark, eds. Product Integrated $P V$. Invited book chapter for Comprehensive Renewable Energy. Vol. 1: Photovoltaic Solar Energy. 2012, Elsevier. 709-732.

[16] Eggink, W. "Where's My Robot? Integrating Human Technology Relations in the Design Curriculum". In: Proceedings of International Conference on Engineering and Product Design Education; Human Technology Relations. 2014. Enschede: The Design Society. pp. 87-92.

[17] Eggink, W. and Adri Albert de la Bruheze. "Design Storytelling with Future Scenario Development; envisioning "the museum"'". In: Proceedings of Cumulus 2015. In print. Milan.

[18] Eggink, W., A. Reinders, and B.v.d. Meulen. "A practical approach to product design for future worlds using scenariodevelopment". In: Proceedings of 11th Engineering and Product Design Education Conference; Creating a better world. 2009. Brighton: Institution of Engineering Designers.

[19] Dorrestijn, S., M. Van der Voort, and P.-P. Verbeek, "Future user-product arrangements: Combining product impact and scenarios in design for multi age success". Technological Forecasting \& Social Change, 2014. 89: pp. 284-292.

[20] Reinders, A., J.d. Borja, and A.d. Boer. "Product-Integrated sustainable energy technologies - Six years of experiences with innovation and sustainability". In: Proceedings of IASDR 2011, Diversity and Unity. 2011. Delft: International Association of Design Research Societies.

[21] Eggink, W. and A. Reinders. "The Design and Styling of Technology-based Innovations". In: Proceedings of IASDR 2013, Consilience and Innovation in Design. 2013. Tokyo: International Association of Design Research Societies. pp. 001012.

[22] Reinders, A.H.M.E., M. Wiesenfarth, and R.R. King. "Conceptual product development with integrated concentrating PV systems - CPV in the built environment from a designer's perspective". In: Proceedings of 39th IEEE Photovoltaic Specialists Conference. 2013. Tampa (FL), USA: IEEE.

[23] Reinders, A., J.C. Diehl, and H. Brezet, eds. The Power of Design: Product Innovation in Sustainable Energy Technologies. 2012, Wiley: West Sussex. 331.

[24] Reinders, A. and W. Eggink. "PV powered Products: The Future is Design and Styling.". In: Proceedings of European Photovoltaic Solar Energy Conference and Exhibition (EU PVSEC). 2015. Hamburg.

[25] Eggink, W., "The Design \& Styling of Future Products", In: The Power of Design: Product Innovation in Sustainable Energy Technologies, A. Reinders, J.C. Diehl, and H. Brezet (Eds.). 2012, Wiley: West Sussex. pp. 89-99.

[26] Eggink, W. "Disruptive Images: stimulating creative solutions by visualizing the design vision.". In: Proceedings of 13th Engineering and Product Design Education Conference; Creating a better world. 2011. London: Institution of Engineering Designers.

[27] Reinders, A., G. Doudart de la Grée, A. Papadopoulos, A. Rosemann, M.G. Debije, M. Cox, and Z. Krumer. "Leaf Roof Designing Luminescent Solar Concentrating PV Roof Tiles". In: Proceedings of 43rd Photovoltaic Specialists Conference (PVSC). 2016. Portland: IEEE. pp. 3447 - 3451. 